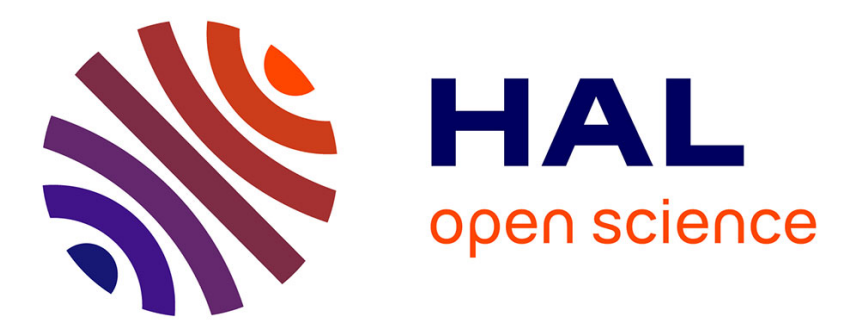

\title{
STABILITY AND ELECTRONIC PROPERTIES OF VACUUM-EVAPORATED AMORPHOUS METALLIC Au-Ge ALLOY FILMS
}

V. Nguyen Van, M. Thèye, Serge Fisson

\section{- To cite this version:}

V. Nguyen Van, M. Thèye, Serge Fisson. STABILITY AND ELECTRONIC PROPERTIES OF VACUUM-EVAPORATED AMORPHOUS METALLIC Au-Ge ALLOY FILMS. Journal de Physique Colloques, 1980, 41 (C8), pp.C8-489-C8-492. 10.1051/jphyscol:19808122 • jpa-00220219

HAL Id: jpa-00220219

https://hal.science/jpa-00220219

Submitted on 1 Jan 1980

HAL is a multi-disciplinary open access archive for the deposit and dissemination of scientific research documents, whether they are published or not. The documents may come from teaching and research institutions in France or abroad, or from public or private research centers.
L'archive ouverte pluridisciplinaire HAL, est destinée au dépôt et à la diffusion de documents scientifiques de niveau recherche, publiés ou non, émanant des établissements d'enseignement et de recherche français ou étrangers, des laboratoires publics ou privés. 


\title{
STABILITY AND ELECTRONIC PROPERTIES OF VACUUM-EVAPORATED AMORPHOUS METALLIC AU-Ge ALLOY FILMS
}

\author{
V. Nguyen Van, M.L. Thèye and S. Fisson \\ Laboratoire d'optique des solides ${ }^{\dagger}$, Université Pierre et Marie Curie, 4, place Jussieu, \\ 75230 Paris Cédex 05, France.
}

\begin{abstract}
Résumé. - On discute les conditions d'existence et la stabilité d'alliages métalliques amorphes Au-Ge préparés par co-évaporation sous ultra-vide. Leurs propriétés optiques sont analysées en contribution de Drude et contribution interbande. On en déduit la présence d'hybridation sp-d dans ces alliages.
\end{abstract}

Abstract. - The existence and stability of amorphous metallic Au-Ge alloys prepared by co-evaporation under ultra-high vacuum are discussed. Their optical properties are analysed in terms of a Drude and an interband contribution.occurrence of sp-d hybridization is inferred.

1. Introduction. - Amorphous metallic alloys between a noble metal and $\mathrm{Si}$ or Ge have been obtained by different methods (1-5). Their main interest lies in the relative simplicity of the electronic structure of either component. The complex dielectric constant of pure noble metals follows a freeelectron behavior up to 2-4 ey, where a strong interband contribution, due essentially to transitions between the filled d-band and the Fermi level, sets in. These properties are littlé modified in the liquid state (6). Si and Ge are covalent in their solid (crystalline and amorphous) state, due to $s p^{3}$ hybridization, but metallic in their liquid state, with about four conduction electrons per atom. These alloys are therefore good candidates for testing the validity of a rigid-band model, in which $\mathrm{Si}$ or Ge impurities would just add their four valence electrons to the host conduction band. The optical properties of sputtered amorphous $\mathrm{Au}-\mathrm{Si}$ alloys for Si concentrations between 13 and 50 at.\% have recently been interpreted as confirming such a model (7). However, the situation may not be so simple, because of the strong interaction which can be expected between the impurity $s-p$ states and the host $d$ states ( 8 ). Moreover, the type of bonding is likely to change, at least locally, when increasing the $\mathrm{Si}$ or Ge concentration, which will alter the metallic character of the alloys.

We present here the results of ootical measurements on amorphous $\mathrm{Au}-\mathrm{Ge}$ alloys with Ge concentrations between 20 and 40 at.\%. These alloys were prepared by co-evaporation under ultra-high vacuum

† Equipe de Recherche Associée au CNRS n ${ }^{\circ} 462$ in order to avoid spurious effects due to built-in gazeous impurities. Their structure was controlled by electrical resistance measurements and electron microscope investigations. We discuss briefly the existence and stability of amorphous metallic alloys and we analyse their optical properties in relation with different mode1s for their electronic structure

2. Experiment. - The samples are thin (200-400 \&) semi-transparent films deposited by co-evaporation under ultra-high vacuum onto glass substrates maintained at low temperature $(15-20 \mathrm{~K})$. The deposit composition and thickness are monitored by two ca1ibrated quartz microbalances. The film reflectance and transmittance are measured in situ just after deposition, between 0.6 and $4.5 \mathrm{ev}$, with a specialIy built spectrometer (9). Electrical d.c. resistance measurements performed in situ by a fourprobe technique as a function of temperature allow to characterize the as-deposited sample, to determine its stability range and to follow possible structural changes on annealing. Optical measurements are repeated in situ at any desired annealing stage. At room temnerature, they are performed both under vacuum and in air with a Cary 14 spectrometer, as a check of the optical data accuracy. The structure of the as-deposited film and its changes upon annealing are traced back from room temperature electron diffraction and electron microscopy results, supplemented by a detailed analysis of the annealing curve. The film thickness is determined by an X-ray interference method (10), its composition by an electron microprobe technique (11). 
3. Existence and stability of amorphous alloys. only the main results are given here. The details of electrical resistance measurements and structure investigations will be reported elsewhere (12).

- For sma11 Ge concentrations (5, 11 at.\%) the films always consist in a mixture of pure Au and pure Ge crystallites.

- For Ge concentrations closer to the eutectic, 27 at.\% Ge (13) $(24,28,30$ at.\%), we obtained amorphous alloys whose structure is characterized by two unsplit broad diffraction rings centred at $s=\sin \theta / \lambda=0.217$ and $0.380 \AA^{-1}$ respectively. This diffraction pattern is very similar to the one reported for a liquid $\mathrm{Au}_{75} \mathrm{Ge}_{25}$ alloy (14) and indicates a simple, close-packed structure with no Ge-Ge bond. These amorphous alloys have initial resistivities between 124 and $138 \mu \Omega \mathrm{cm}$, with very sma11 negative temperature coefficients: -4 to $-7 \times 10^{-5}$. Crystallization starts above $250 \mathrm{~K}$ with the precipitation of pure Au microcrystallites and, in some cases, the formation of a metastable complex crystalline alloy phase.

- For higher fe concentrations (34 at.\%), we still obtained amorphous alloys, but with a different structure. Their diffraction diagrams present an additional broad ring centred at $s=0.155 \AA^{-1}$ reminiscent of the first diffraction ring of pure amorphous $G e$ (15). These amorphous alloys have slightly higher resistivities, with more negative temperature coefficients, of the order of $-5 \times 10^{-4}$. A metastable complex crystalline alloy phase, different from the previous one, appears abruptly just below room temperature.

4. Analysis of optical data. - Measuring both the reflectance $R$ and the transmittance $T$ of a thin film with known thickness allows to determine the complex dielectric constant $\tilde{\varepsilon}=\varepsilon_{1}+i \varepsilon_{2}$ accurately at each frequency (16). Unfortunately, in the present case, the computed $\tilde{\varepsilon}$ values are extremely sensitive to even very small experimental uncertainties on $R$ and $T$, which, besides, vary very little with frequency, especially in the near infra-red.

- For Ge compositions between 20 and 30 at.\%, the $\varepsilon_{1}$ and $\varepsilon_{2}$ curves for the as-deposited amorphous alloys are significantly different from those for pure Au (figure 1). A metallic behavior is still observed at low energies but the optical absorption is considerably enhanced; an absorption edge

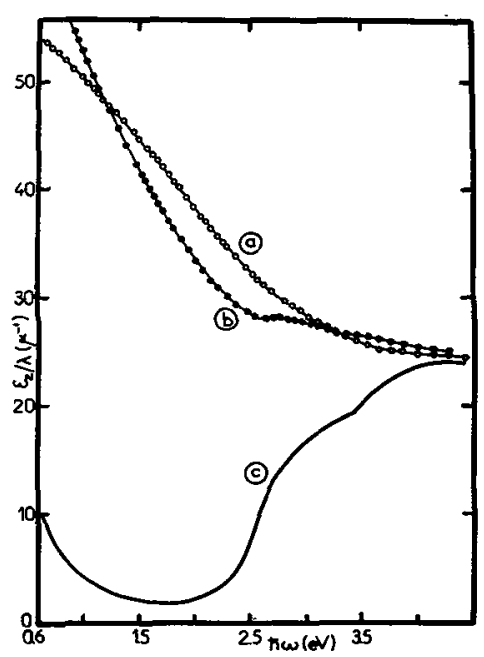

Figure 1. - Optical absorption $\varepsilon_{2} / \lambda$ for a $\mathrm{Au}_{70} \mathrm{Re}_{30}$ alloy: amorphous (a) and partially crystallized (b), and for pure $\mathrm{Au}$ (c).

reminiscent of the onset of interband transitions in pure Au is difficult to detect at higher energies (such an edge shows up immediately when pure Au crystallites appear on annealing, as shown by curve (b) in figure 1).

We tentatively analysed the low energy data in terms of a Drude model which, even in a disordered system, should represent a first approximation to the ontical properties associated with conduction electrons:

$$
\tilde{\varepsilon}=1-\omega_{D}^{2} / \omega\left(\omega+i / \tau_{0}\right)+\varepsilon_{1}^{c}
$$

where $\omega_{\mathrm{D}}=\left(4 \pi \mathrm{N}_{\mathrm{eff}} \mathrm{e}^{2 / \mathrm{m}_{\mathrm{o}}}\right)^{1 / 2} \quad\left(\mathrm{~N}_{\mathrm{eff}}\right.$ the effective number of electrons per unit volume and $m_{0}$ the optical effective mass) is the plasma frequency and $\tau_{0}$ the optical relaxation time of the conduction electrons; the constant real term $\varepsilon_{1}^{c}$ accounts for interband transitions occurring at higher energies. Computer-fitting procedures on $\left(\varepsilon_{1}, \varepsilon_{2}\right)$ or directly on ( $R, T$ ), as well as graphical methods, were used to determine $\omega_{p}, \tau_{0}$ and $\varepsilon_{1}^{c}$. Reasonable agreement with a simple Drude model was found from 0.6 us to $2.5 \mathrm{ev}$. Allowing the relaxation time to be frequency-dependent did not improve the fit significantly. We found for $x_{\mathrm{Ge}}=30$ at.\% (with $\left.\varepsilon_{1-2}^{c} \sim 2.5\right): \hbar \omega_{p}=14.20 \mathrm{eV} ; \hbar / \tau_{0}=2.85 \mathrm{eV}$.

Above $2.5 \mathrm{eV}$, there is an additional contribution to the optical absorption which can be attributed to interband transitions (figure 2). It is much smaller than in pure $\mathrm{Au}$ and presents a very smooth edge, which makes any'onset energy very difficult to determine. 


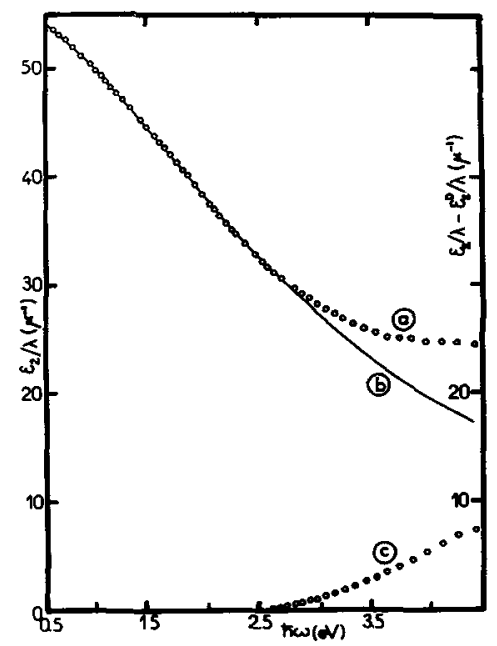

Figure 2. - Decomposition of $\varepsilon_{2} / \lambda$ for an amorphous $\mathrm{Au}_{70} \mathrm{Cre}_{30}$ alloy (a) into a Drude term (b) and an interband term (c).

- For larger Ge concentrations, the optical spectra corresponding to the as-deposited amorohous alloys are completely different from the previous ones (figure 3 ). There is a strong absorotion maximum in the visible, centred at about $2.4 \mathrm{eV}$, and no metallic behavior can be detected over the investigated spectral range. Little change is observed through crystallization.

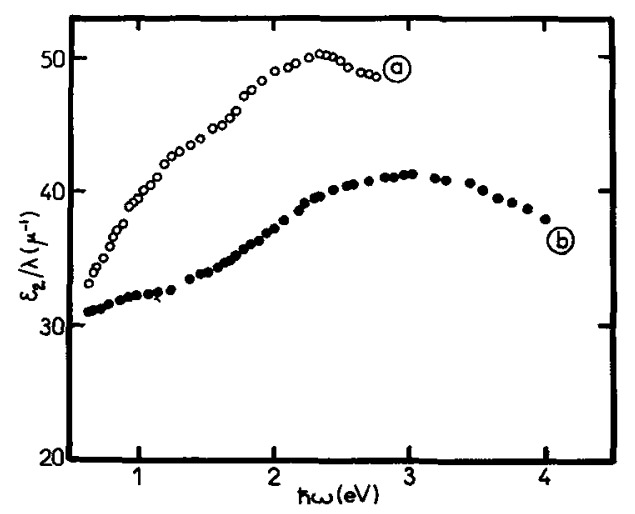

Figure 3. - Optical absorption $\varepsilon_{2} / \lambda$ for a $\mathrm{Au}_{6 \mathrm{Ge}}$ alloy: amorohous (a) and partially crystallized into a complex crystalline phase $(\gamma$-AuGe) (b).

5. Discussion. - By co-evaporation under ultrahigh vacuum, amorphous metallic Au-Ge alloys could be obtained over a small composition range only and their stability was very limited. For higher fe contents, although the films were still amorphous, loca1 changes in bonding, perhaps favoured by composition fluctuations, modified the electronic properties of the alloys, optically they were no more metallic. Different results were obtained on sputtered amorphous Au-Si alloys which, in spite of a structure change above 40 at.\% $\mathrm{Si}$ (5), had a meta1lic optical behavior up to 50 at.\% Si (7).

The odtical oroperties of the amorphous metallic $\mathrm{Au}-\mathrm{Ge}$ alloys are nevertheless very similar to those of amorohous (7) and liquid (17) metallic Au-Si alloys. All data follow a Drude 1 aw in the near infra-red, with comparable values of the parameters characterizing the conduction electrons behavior. Extremely short relaxation times $\tau_{0}$ are deduced, about an order of magnitude smaller than in pure liquid noble metals (6) but of the same order of magnitude as in pure liquid Ge (18). The effective number of conduction electrons which can be deduced from $\omega_{p}$, assuming that the ontical mass is equal to the free-electron mass, is quite high: about 2.5 electron per atom on average for $x_{G e}=30$ at.\% if we take the same atomic density as in pure $\mathrm{Au}$ (19). This value is much larger than the one computed in a rigid band model, about 1.9 . In all cases, there is an additional contribution to the optical absorption at energies where interband transitions from the $d$ band occur in pure $A u$, but it is considerably smoothed out.

Al1 these results suggest that a simple rigid band model cannot be applied, and that the Au conduction band and $d$ band are significantly a1tered when alloying with $\mathrm{Ge}(\mathrm{Si})$. It has been shown theoretically (8) that the electronic structure of a $\mathrm{Si}$ impurity in a $\mathrm{Cu}$ matrix is deeply modified by sp-d hybridization. This theory explains the characteristic anti-resonant structure observed in the p-partial density of states around $\mathrm{Si}$ atoms in dilute $\mathrm{Cu}-\mathrm{Si}$ alloys by soft X-ray emission (20). A conduction band being far from free-electronlike is therefore expected in the alloys. This conclusion, which was also inferred from magnetic susceptibility measurements on liquid $\mathrm{Au}_{81} \mathrm{Si}_{19}$ alloy (21), is more compatible with the values of the parameters characterizing the conduction electron behavior deduced from the optical data. The sp-d hybridization is also likely to modify the d-partial density of states. A shift of the upper peak of the Au d band towards lower energies, accompanied by a smoothing of the upper edge, has been observed for evaporated amorphous $\mathrm{Au}-\mathrm{Ge}$ alloys (20 and 40 at.\% Ge) by photoemission (3). Such an effect would explain, better than disorder alone, the experimental reduction of the interband 
absorption.

Acknowledgement. - The research reborted herein has been sponsored in part by the European office of Aerospace Research and Development.

\section{References}

(1) KLEMENT, W., WILLENS, R.H. and DUNEZ, P., Nature 187 (1960) 869.

(2) CHEN, H.S. and IURNBUtL, D., J. Adp1. Phys. 38 (1967) 3646.

(3) FUKUSHIMA, J., TAMURA, K., ENDO, H., KISHI, K., IKEDA, S. and MINOMURA, S., J. Phys. 35 (1974) C4-261.

(4) HIRAKI, A., IWAMI, M., SHIMIZU, A. and SHUTO, K., Mater. Sci. Eng. 23 (1976) 289.

(5) HAUSER, J.J. and TAUC, J., Phys, Rev. B17 (1978) 3371 .

(6) HODGSON, J.N., Phil. Mag. 5 (1960) 272.

(7) HAUSER, E., ZIRKE, R.J., TAUC, J., HAUSER, J.J. and NAGEL, S.R., Phys. Rev. Lett. 40 (1978) 1733; Phys. Rev. B19 (1979) 6331.

(8) TERAKURA, K., J. Phys. Soc. Japan 40 (1975) 450 .

(9) NGUYEN VAN, $V$, and FISSON, S., Revue Phys. App 1. 13 (1978) 155

(10) KIESSIG, H., Ann. Physik 10 (1931) 769; UMRATH, W., Z. Angew. Physik 22 (1967) 406

(11) PHILIBERT, J., RIVORY, J.; BRYCYAERT, D. and TIXIER, R., J. Phys. D: Appl. Phys. 3 (1970) L70.
(12) NGUYEN VAN, V., FISSON, S, and THEYE, M.L., to be published in the Proceedings of the 8 th Int. Vacuum Congress (Cannes, France, 1980).

(13) HANSEN, M., Constitution of binary alloys (McGraw Hill, New-York) 1958.

(14) WAGHORNE, R.M., RIVLIN, V.G. and WILLIAMS, G.I., J. Phys, F: Metal Phys. 6 (1976) 147.

(15) GANDAIS, M., THEYE, M.L., FISSON, S. and BOISSONADE, J., Phys. Stat. Sol. (b) 58 (1973) 601 .

(16) ABELES, F. and THEYE, M.L., Surf. Sci. 5 (1966) 325 .

(17) ACKERMANN, K.P., LIARD, M. and GUNTHERODT, H.J., to be published in J. Phys. F: Metal Phys.

(18) HODGSON, J.N., Phil, Mag. 6 (1961) 509.

(19) MANGIN, P., MARCHAL, G., MOUREY, C. and JANOT, C., to be published in Phys. Rev. $B$.

(20) TANAKA, K., MATSUMOTO, M. and MARUNO, S., Anpl. Phys. Lett. 27 (1975) 529.

(21). BAGLEV, B.G. and DI SALVO, F.J., Bu11. Am. Phys. Soc. 21 (1976) 385. 